\title{
The temporal evolution of three-dimensional lightning parameters and their suitability for thunderstorm tracking and nowcasting
}

\author{
V. K. Meyer ${ }^{1, *}$, H. Höller ${ }^{1}$, and H. D. Betz ${ }^{2,3}$ \\ ${ }^{1}$ Deutsches Zentrum für Luft- und Raumfahrt, Institut für Physik der Atmosphäre, Oberpfaffenhofen, 82234 Wessling, \\ Germany \\ ${ }^{2}$ University of Munich, Department of Physics, 85748 Garching, Germany \\ ${ }^{3}$ nowcast GmBH, 81377 Munich, Germany \\ *now at: Zentralanstalt für Meteorologie und Geodynamik, 1190 Vienna, Austria
}

Correspondence to: V. K. Meyer (vera.meyer@zamg.ac.at)

Received: 29 September 2012 - Published in Atmos. Chem. Phys. Discuss.: 22 January 2013

Revised: 18 April 2013 - Accepted: 22 April 2013 - Published: 22 May 2013

\begin{abstract}
Total lightning (TL) data have been found to provide valuable information about the internal dynamics of a thunderstorm allowing conclusions about its further development as well as indicating potential of thunderstormrelated severe weather at the ground. This paper investigates electrical discharge correlations of strokes and flashes with respect to the temporal evolution of thunderstorms in case studies as well as by statistical means. The recently developed algorithm li-TRAM (tracking and monitoring of lightning cells, Meyer et al., 2013) has been employed to track and monitor thunderstorms based on three-dimensionally resolved TL data provided as stroke events by the European lightning location network LINET. From statistical investigation of 863 suited thunderstorm life cycles, the cell area turned out to correlate well with (a) the total discharge rate, (b) the in-cloud (IC) discharge rate, and (c) the mean IC discharge height per lightning cell as identified by li-TRAM. All three parameter correlations consistently show an abrupt change in discharge characteristics around a cell area of $170 \mathrm{~km}^{2}$. Statistical investigations supported by the comparison of three case studies - selected to represent a single storm, a multi-cell and a supercell - strongly suggest that the correlation functions include the temporal evolution as well as the storm type. With the help of volumetric radar data, it can also be suggested that the well-defined break observed at $170 \mathrm{~km}^{2}$ marks the region where the transition occurs from short-lived and rather simple structured single storm cells to better organized, more persistent, and more complex structured thunderstorm forms, e.g. multi-cells and supercells. All
\end{abstract}

three storm types experience similar discharge characteristics during their growing and dissipating phases. However, while the poorly organized and short-lived cells preferentially remain small during a short mature phase, mainly the more persistent thunderstorm types develop to sizes above $170 \mathrm{~km}^{2}$ during a pronounced mature stage. At that stage they exhibit on average higher discharge rates at higher altitudes as compared with matured single cells. With the maximum stroke distance set to $10 \mathrm{~km}$ and a flash duration set to $1 \mathrm{~s}$, the parameterization functions found for the stroke rate as a function of the cell area have been transformed to a flash rate. The presented study suggests that, with respect to the storm type, stroke and flash correlations can be parameterized. There is also strong evidence that parameterization functions include the time parameter, so that altogether TL stroke information has good potential to pre-estimate the further evolution (nowcast) of a currently observed storm in an object-oriented thunderstorm nowcasting approach.

\section{Introduction}

The imposing appearance of lightning has always prompted the attempt to understand the phenomenon and therewith been a topic for natural sciences. With the ongoing evolution of lightning detection systems, lightning data experience more and more attention in meteorological and climatological applications. One focus is on the use of lightning data to identify and pursue (electrically active) thunderstorms and 
to look for similarities in their electrical evolution, which can be used to improve the prediction of their development (nowcasting). Another focus is to understand the physical processes, which finally lead to electrical discharges in the cloud, in order to reproduce realistic lightning flashes in weather models.

The electrical development has been found strongly connected to the dynamical and microphysical development of a thunderstorm. Several mechanisms contribute to the cloud electrification in convective storms (MacGorman and Rust, 1998; Saunders, 2008), but the non-inductive (NIC) charging mechanism has been identified as the mainly responsible process (Takahashi, 1978; Dash et al., 2001; Saunders, 2008) closely tying the cloud electrification to the storm updraft region(s). Thus, the storm structure should affect the discharge characteristics, which might provide indication of the storm structure and type.

Numerous studies have examined the temporal evolution of observable features, such as volumetric storm growth and decay, the development of updrafts and downdrafts, hydrometeor formation, precipitation, and - finally - electrical activity, within a typical thunderstorm life cycle aiming to relate their physical and temporal interactions with the storm's growing stage, mature stage, and dissipation stage.

In these studies, positive correlations have been found between peak flash rates and storm parameters such as updraft strength, storm size, and cloud top height (Williams, 1985; Krehbiel, 1986; Price and Rind, 1992; Allen and Pickering, 2002; Motley et al., 2006), between total lightning (TL) discharge characteristics (in-cloud (IC) to cloud-to-ground (CG) occurrence), and changes in the upper storm bulk microphysics (Lopez and Aubagnac, 1997; Fehr et al., 2005). Also, the influence of storm duration and environmental conditions on electrical storm development has been explored and found important (Goodman and MacGorman, 1986; Fehr et al., 2005).

Ambivalent studies exist about a possible correlation between mean altitude of IC discharges and updraft strength. It has been noted that an increase in updraft strength lofts the positive charge region to higher elevations (Shao and Krehbiel, 1996). So it can be expected that storm cells with stronger updrafts have higher mean lightning flash heights than storm cells with weaker updrafts, as it has been found for two storm cases investigated in McCormick et al. (2002). This would give reason to expect that the IC mean discharge height reflects the storm state, being highest during the mature state, as it is presented for one exemplary storm studied in Demetriades et al. (2004). In contrast thereto Motley et al. (2006) could not find this clear correlation in a more detailed study based on 26 storm cases. But due to the limitations of the detection systems, these studies are restricted to small areas and a limited sample of suitable case studies.

In parallel to these studies, several more or less advanced phenomenological approaches arose, to correlate flash rates with other observable storm features like (cold) cloud depth
(Price and Rind, 1992; Yoshida et al., 2009) or updraft strength (Blyth et al., 2001; Deierling and Petersen, 2008). Those parameterization functions have been applied to parameterize flash rates in models, where convection cannot be resolved. As it is discussed in detail in Dahl et al. (2011), all these "single-parameter" approaches, which derive flash rates from only one other storm parameter, simply cannot be capable of reproducing the electrical development of an individual storm correctly. Since there is strong evidence that close correlations exist, they still seem to be feasible methods to obtain general guesses for flash rates. However, it has to be kept in mind that every single-parameter approach gives, at best, the mean behaviour.

Motivation of this paper is a profound investigation on the extended information content of LINET lightning data (IC/CG discrimination with IC altitude information). The focus is laid on storm-dependent discharge similarities and with respect to the extensive coverage - their potential for operational thunderstorm nowcasting. Since 2005 the VLF/LF lightning detection network LINET has provided threedimensionally resolved total lightning data for an area as large as central Europe in real time (Betz et al., 2009, 2007). The principal suitability of LINET lightning data for thunderstorm nowcasting has already been demonstrated (Betz et al., 2008; Meyer et al., 2013). In the present study correlations between discharge characteristics, storm size, type and longevity have been investigated by using the lightningcell tracker li-TRAM, which has been recently developed at the German Aerospace Center (DLR) (Meyer et al., 2013). Hereby, general correlations are in focus as well as the temporal evolution. The cell tracker has been employed on LINET stroke data. But whenever lightning characteristics of different lightning localization systems are compared, a basic problem arises due to different set-ups and data postprocessing methods (Cummins and Murphy, 2009). In order to provide the best possible device-independent and therewith universally comparable results, a time-distance criteria method has been used to translate the results into common flash information. A stroke is assigned to a flash when it is recorded less than $1 \mathrm{~s}$ after and located within a distance of $10 \mathrm{~km}$ to the first stroke. These criteria to cluster strokes to flashes are adopted from other prominent lightning detection systems, which are comparable to LINET, like the National Lightning Detection Network (NLDN) and the European Cooperation for Lightning Detection (EUCLID) (Cummins and Murphy, 2009; Burrows et al., 2002; Schulz et al., 2005; EUCLID, 2012).

Volumetric radar data are used in case studies to assist in the interpretation and to corroborate the conclusions.

\section{Methods and data}

For this study the new thunderstorm tracking algorithm li-TRAM has been used to identify, track and monitor 
thunderstorms based on lightning data provided by LINET. Li-TRAM has been recently developed at the DLR and, as one constituent of the hybrid thunderstorm tracking algorithm ec-TRAM, successfully evaluated for LINET stroke data (Meyer et al., 2013).

Li-TRAM identifies and tracks lightning cells over time using time sequences of two-dimensional lightning-cell maps. The feature of prediction of future cell positions is not the subject of this study. The following paragraph summarizes the method, parameter settings, and data preprocessing used for the study. A detailed description is given in Meyer et al. (2013). Lightning-cell maps are generated every $2.5 \mathrm{~min}$ starting with mapping the lightning data of the previous $3 \mathrm{~min}$ on a basic grid with a horizontal resolution of $0.01^{\circ}$ longitude $\times 0.005^{\circ}$ latitude (approximately $0.7 \mathrm{~km} \times 0.55 \mathrm{~km}$ ). Every stroke event is allocated to the nearest grid point counting the total number of events per grid point. Based on this "intensity map", discrete discharge events are clustered to coherent discharge areas by using a maximum search radius of 7 pixels (approximately $4.5 \mathrm{~km}$ ). The final lightning-cell outlines, which are finally drawn on the lightning-cell map, are defined by enlarging the identified coherent discharge areas by three more pixels (approx. $2 \mathrm{~km}$ ) in each direction to achieve more generous cell outlines. This is reasonable since the potentially electrically active region most likely exceeds the outermost recorded lightning strokes of a lightning-cell object. All calculated cell parameters, such as cell area, number of strokes per cell and mean IC emission height, refer to the so-defined cell objects. Stroke and flash rates of a cell object, which are analysed in the following, are normalized to one-minute discharge activity. The single-cell objects are tracked from one time step to the next by identifying cell overlaps between current and previous cell outlines. The cell parameters are stored in respective log files recording the cell history. Since the accumulation intervals overlap by $0.5 \mathrm{~min}$, active lightning regions are supposed to overlap from one time step to the next, as they most likely share same events. Cell splitting is recorded when more than one current lightning cell can be correlated to a previous lightning cell. Cell merging is recorded when more than one previous lightning cell can be correlated to a current lightning cell. Considering a cell splitting, the current cell with the largest area inherits the cell number (and history) of the previous cell and is further tracked. Considering a cell merging, the previous cell, which exhibits the largest overlap with the current cell, passes on its number (and history) and is tracked further. All cells that participate in a merging or splitting event are marked, respectively.

Li-TRAM operates on lightning data provided by the VLF/LF total lightning detection system LINET (Betz et al., 2009, 2007). Continuously refined, LINET locates atmospheric electrical discharges inside the network with rangenormalized currents down to a few $\mathrm{kA}$ and a statistical average localization error of down to $100 \mathrm{~m}$. An adapted version of the common time-of-arrival (TOA) concept enables
LINET to calculate the emission height in addition to the horizontal location (latitude, longitude) and the event time of a discharge source. The additional height parameter allows for a consistent discrimination between IC and cloudto-ground CG strokes which is independent of other stroke parameters. The subsequent analysis is based on pure stroke data. Although the principal decision criterion to discriminate IC and CG strokes is the calculated emission height, further criteria defined for the location error and the distance to the closest sensor (Betz et al., 2009, 2007) are also validated to classify discharge events as "secure IC", "secure CG", or as so-called "undefined" stroke events. While IC and CG statistics refer to those strokes, which could be classified as "secure", TL statistics refers to all recorded strokes including unclassified events.

The following studies are performed on a data set, which was recorded in south Germany from May to September in 2008. The research domain extends within $47.4^{\circ}$ and $49.2^{\circ}$ northern latitude and within $10.3^{\circ}$ and $13.0^{\circ}$ eastern longitude. This region belongs to the densest part of the current sensor network with the highest detection accuracy (Höller et al., 2009; Betz et al., 2009). To avoid that local sensitivity variations in the detection efficiency affect the monitored lightning-cell characteristics impeding a correct interpretation, small peak current data with an absolute value below $2.5 \mathrm{kA}$ were eliminated from the analysis. For the same reason, IC strokes with an emission height below $5 \mathrm{~km}$ were excluded from emission height analyses (not from discharge analyses) (Meyer et al., 2013). A total of $92 \%$ of all recorded CG and $90 \%$ of all recorded IC events meet the amplitude criterion and again $90 \%$ of the IC events with amplitudes of $2.5 \mathrm{kA}$ and higher meet the IC height criterion.

Volumetric radar data have been used in case studies to evaluate the interpretation which otherwise would be based on the li-TRAM output alone. The data were provided by the DLR C-band radar POLDIRAD (polarization diversity Doppler radar; Schroth et al., 1988).

\section{Results and discussion}

In the subsequent discussion the terms cell or cell entry refer to a single-cell object as it is recorded by li-TRAM at one time step. The terms life cycle or cell track refer to the entire time series recorded for a storm as it is tracked over time. In the following, only those cell tracks are considered that lived reasonably long and that were completely assessed as well as recorded as grown and dissipated in an undisturbed manner. This means that the cell tracks were monitored for $35 \mathrm{~min}$ or longer and are neither truncated by the domain margins nor do they originate from a cell splitting nor disappear in a cell merging process. During the observation period a total of 7687 cell entries including 863 complete and undisturbedly developing cell tracks were assessed and are analysed below. 
(a)

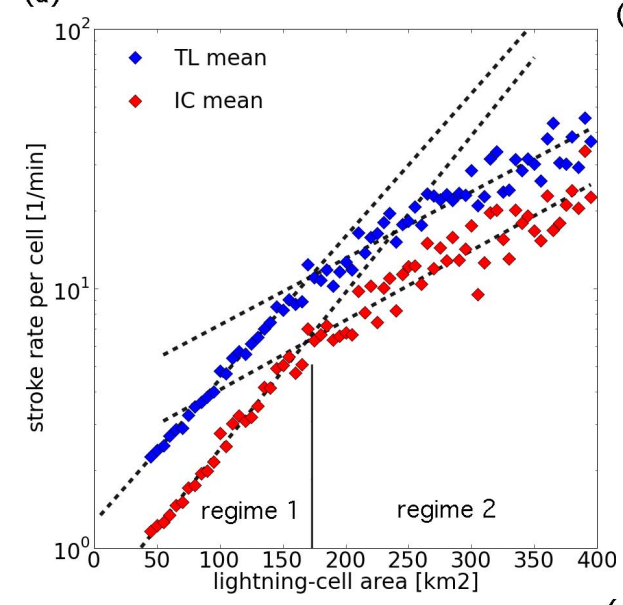

(c)

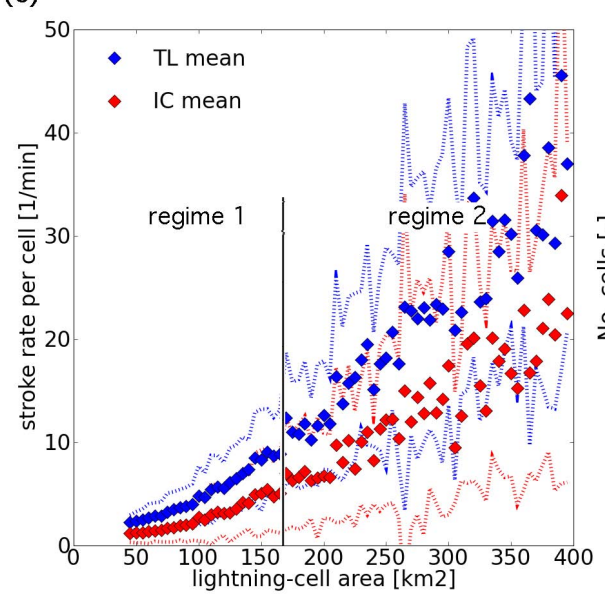

(b)

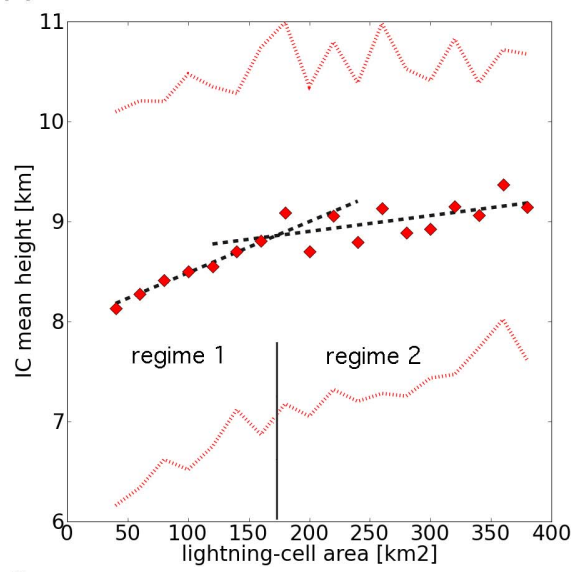

(d)

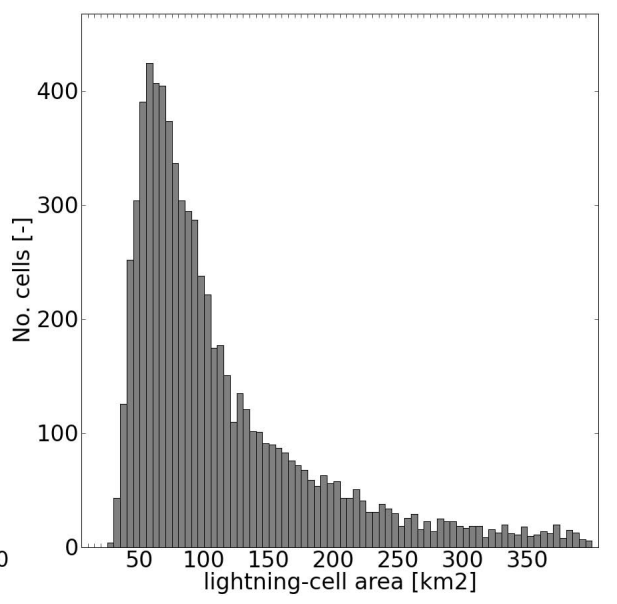

Fig. 1. Correlation diagrams between selected lightning-cell parameters. Respective correlation equations are given in the text. (a) Mean number of TL (blue diamonds) and IC (red diamonds) strokes per lightning cell on logarithmic scale averaged for $5 \mathrm{~km}{ }^{2}$ cell area intervals and their correlation functions (dashed lines). (b) Mean IC emission height per lightning cell averaged for $20 \mathrm{~km}^{2}$ cell area intervals with their 25th and 75th percentile and respective parameterization functions. (c) Mean TL (blue diamonds) and IC (red diamonds) stroke numbers of figure (a) with their 25th and 75th percentile on linear scale. (d) Number statistic of cell entries underlying the analyses shown in figures (a) to (c). In figure (b) and (c) the 25th and 75th percentile of the underlying distribution (dashed lines in respective colour) illustrate the distribution spread.

To calculate the statistical correlation plots shown in Fig. 1, individual cell entries were averaged on equidistant area intervals. Their stroke rates are normalized to oneminute discharge activity. The plots reveal strong, strictly monotonically increasing relations between discharge characteristic and the cell area. The stroke rates per cell show an exponential correlation for both TL and IC events, whereas the mean IC emission per cell follows a linear correlation. In all correlation plots a break in the discharge characteristics can clearly be seen at a cell area around $170 \mathrm{~km}^{2}$, apparently separating two area-discharge regimes. The transition point is found at a TL stroke rate of 10 strokes per minute with a fraction of around 7 IC strokes and a corresponding mean emission height of about $8.7 \mathrm{~km}$. At the transition point all correlation functions change abruptly. On the one hand the inclination decreases (Fig. 1a and b) towards larger cell areas, while on the other hand the mean values abruptly show significant scatter, best visible on the linear scales (Fig. 1b and c). The onset of scatter is not likely caused by insufficient statistics, as it can be seen in Fig. 1d.

Parameterization functions are achieved for both areadischarge regimes by minimizing the mean squared errors $R^{2}$. To calculate the regression functions for both areadischarge regimes, the intervals have been set to range from 15 to $170 \mathrm{~km}^{2}$ for the first and from $170 \mathrm{~km}^{2}$ to $400 \mathrm{~km}^{2}$ for the second regime. For TL stroke rates per minute $\left(r_{\mathrm{TL}}^{\mathrm{str}}\right)$, the parameterizations as a function of the cell area $A$ (in $\mathrm{km}^{2}$ ) are found to be

$$
r_{\mathrm{TL}}^{\mathrm{str}}=1.26 \times 10^{0.0055 A} \quad \text { with } R^{2}=0.93
$$




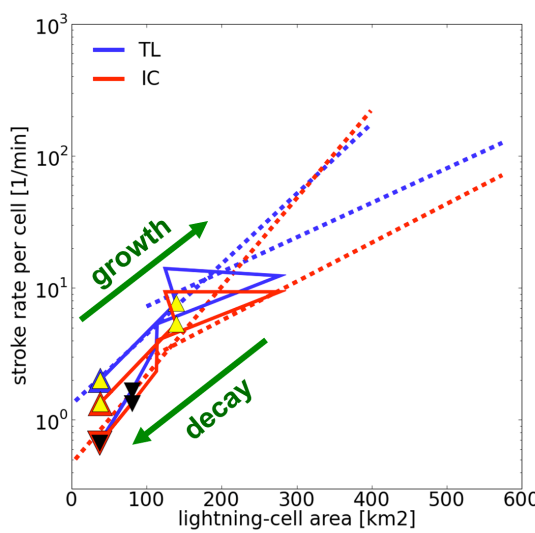

(a)

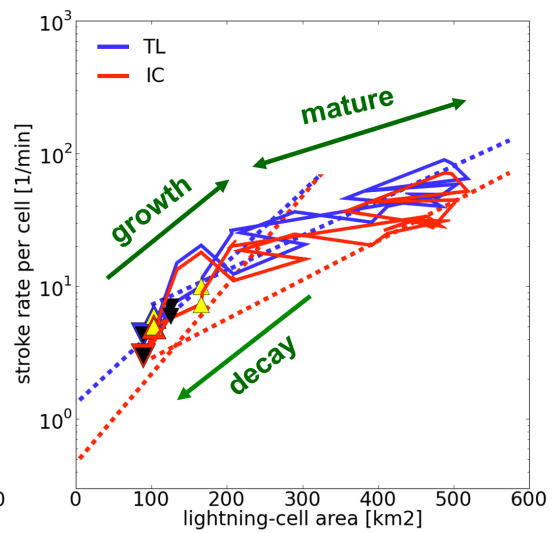

(b)

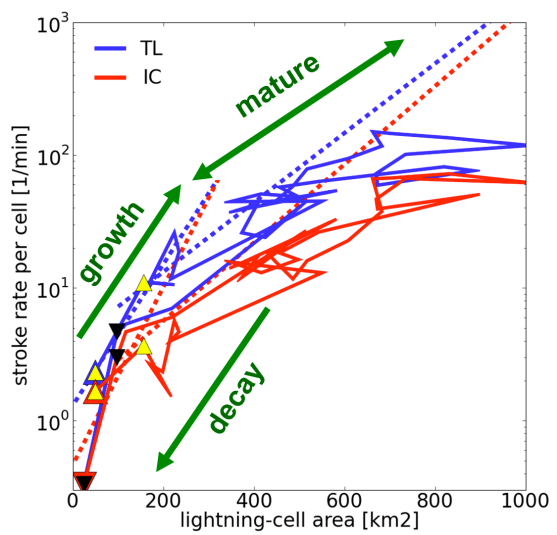

(c)

Fig. 2. The temporal evolution of the TL (blue) and IC (red) frequency and lightning-cell area for three selected thunderstorms of different type: (a) single-cell type thunderstorm, recorded on 30 May 2008 in south Germany, with a lifetime of 40 min; (b) multi-cell type thunderstorm, recorded on 30 May 2008 in south Germany, with a lifetime of $195 \mathrm{~min}$; and (c) supercell type thunderstorm, recorded on 25 June 2008 in south Germany, with a lifetime of $145 \mathrm{~min}$. Each panel shows the respective storm parameter evolution along the solid lines starting from the yellow triangles and ending at the black triangles. The correlation functions of Fig. 1 are shown for TL and IC stroke numbers.

for the first area-discharge regime and for the second regime

$r_{\mathrm{TL}}^{\mathrm{str}}=4.01 \times 10^{0.0026 A} \quad$ with $R^{2}=0.87$.

For the first regime, the IC stroke rate (per minute) $r_{\mathrm{IC}}^{\text {str }}$ per lightning-cell area $A\left(\right.$ in $\mathrm{km}^{2}$ ) yields the parameterization function

$r_{\mathrm{IC}}^{\mathrm{str}}=0.60 \times 10^{0.0060 A} \quad$ with $R^{2}=0.92$

and for the second regime

$r_{\mathrm{IC}}^{\text {str }}=2.20 \times 10^{0.0027 A} \quad$ with $R^{2}=0.81$.

Finally the mean IC emission height $h_{\mathrm{IC}}$ (in $\mathrm{km}$ ) has been parameterized as a function of the lightning-cell area $A$ (in $\mathrm{km}^{2}$ ) by

$h_{\mathrm{IC}}=0.0051 A+7.98 \quad$ with $R^{2}=0.99$

and

$h_{\mathrm{IC}}=0.0016 A+8.56 \quad$ with $R^{2}=0.50$

for the first and the second area-discharge regime, respectively. The comparison between the slope factors of relation 1 and relation 3 and of relation 2 and relation 4 shows that the IC stroke rate increases more steeply with the cell area than the TL stroke rate. Consequently, according to the statistics, the relative contribution of IC strokes to the total TL rate increases as the lightning-cell area grows.

The correlation plots, shown in Fig. 1, rely on solid statistics, but they lack information about individual internal storm developments. To complement this picture, the temporal evolution of the stroke rates as a function of the cell area is shown for three selected case studies in Fig. 2. The case studies have been carefully selected with the help of volumetric radar data so that each case represents a special type of thunderstorm (compare discussion to Fig. 3). Figure 2a shows the parameter correlations of a rather poorly organized, shortlived storm (lifetime of $40 \mathrm{~min}$ ), which was recorded on 30 May 2008. This storm has been found representative of the single-storm class. Figure $2 \mathrm{~b}$ shows the correlation graph of a well-organized and long-lived storm (lifetime of $195 \mathrm{~min}$ ), which has been clearly classified as multi-cell in its mature stage (compare Fig. 3b). It developed also in the afternoon of 30 May 2008 south of Munich. Finally, Fig. 2c shows the correlation diagram of another well-organized and longlived storm (lifetime of $145 \mathrm{~min}$ ), which showed supercell features in its mature stage (compare Fig. 3c). The storm was recorded in the afternoon of 25 June 2008 south of Munich.

Comparing the three correlation graphs of Fig. 2, similarities but also clear differences can be seen between the poorly organized and short-lived storm and the two highly organized and long-lived storms. All three storms undergo a clear temporal evolution, generally following the parameterization functions given in Eqs. (1) to (4). Initially, as the storms are still growing, their stroke frequencies increase with increasing cell areas. During their final phases, as the storms decease, their stroke frequencies decrease with decreasing cell areas. The mature state of the short-lived cell only lasts about $10 \mathrm{~min}$, where the stroke frequency and the cell area reach their maxima. As opposed to this, the mature state of the long-lived storms is very well pronounced reaching larger cell areas with higher stroke rates and higher IC mean heights. During their mature stage the storms grow into the second area-discharge regime and remain there for about $120 \mathrm{~min}$ in the case of the supercell and for about $150 \mathrm{~min}$ in 

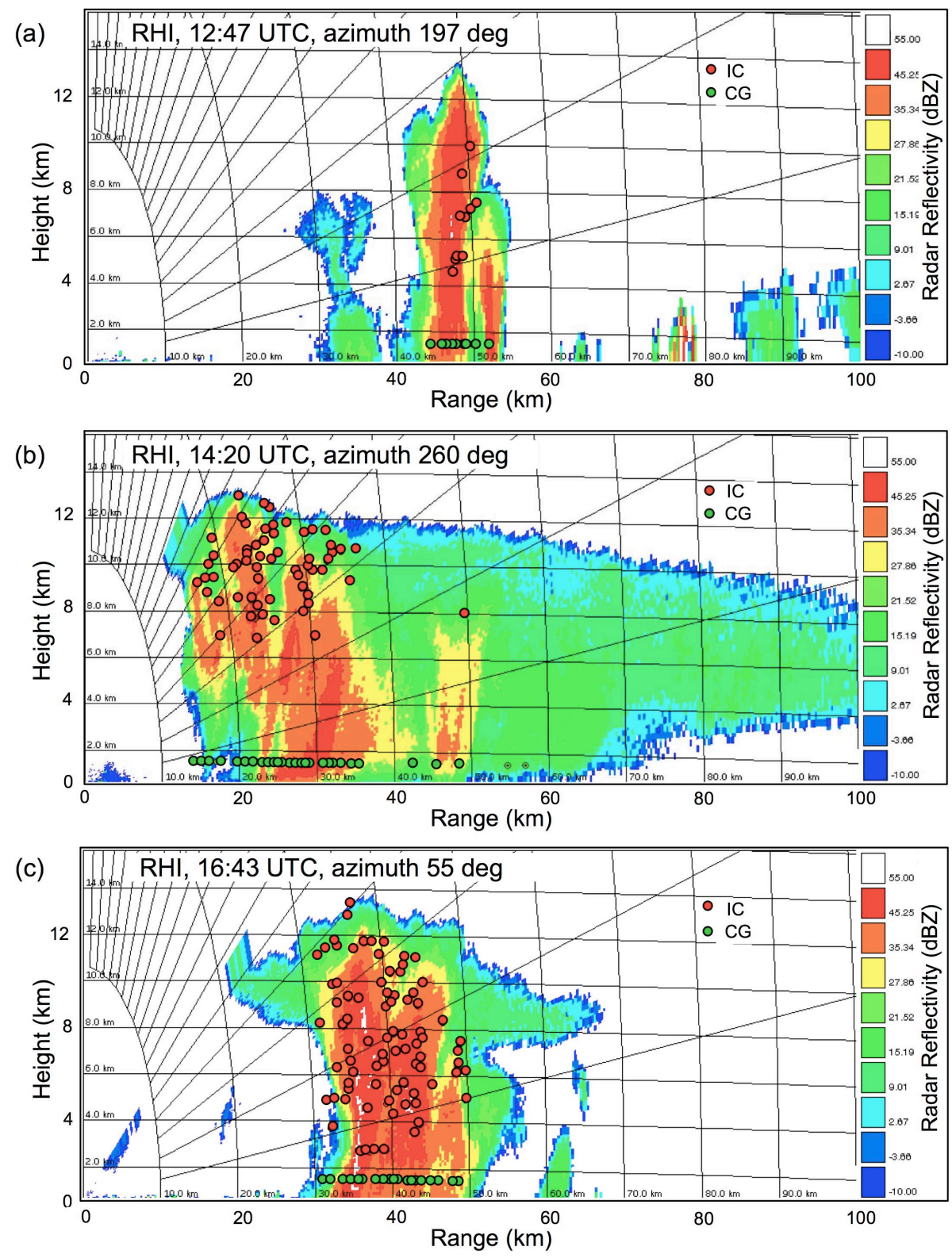

Fig. 3. Selection of vertical radar scans recorded by the DLR radar POLDIRAD. Electrical discharge events recorded by LINET from 2 min prior to $2 \mathrm{~min}$ after the radar mapping times are illustrated. Red dots indicate IC events, green CG events. To better visualize distant CG events, the LINET ground strike points are plotted at $1.5 \mathrm{~km}$ height. (a) The cross section of the multi-cell example at a young stage, characterized by two compact high reaching cell cores. (b) The cross section of the multi-cell storm in its mature stage. (c) The cross section of the supercell example during its mature stage.

the case of the multi-cell storm. For the supercell the TL and IC stroke rates in the second area-discharge regimes exceed the numbers given by the parameterization functions, while for a multi-cell the rates remain below the ones given by the parameterization functions. The transition point, identified in Fig. 1 at $170 \mathrm{~km}^{2}$, is also clearly visible in all three case studies. It appears that it marks the transition from the growing to the mature phase, and then from the mature to the dissipating phase.
Together with the radar cross-section scans presented in Fig. 3a, reasonable interpretation can be derived. Unfortunately, the single-cell type storm developed too close to the radar site to obtain a representative vertical radar scan. Instead, a cross-section scan of the multi-cell storm at an early stage is shown in Fig. 3a. At that stage the storm still has single-cell structure, where a single reflectivity core, indicating the updraft region, towers as a narrow column. Figure $3 b$ shows a radar cross section recorded at a later time, when 
the multi-cell structure has been fully developed. At higher levels the updraft is subdivided into individual cells, each 5 to $10 \mathrm{~km}$ in diameter. Towards lower levels these cells partly merge. Cells at different development stages, from young and growing (left cells) to older and dissipating (right cells), compose the multi-cell storm. Considering the ground projection of the strokes, as li-TRAM does, the storm is assessed as one unity, where each internal cell contributes to the lightning cell statistics. The supercell, presented as cross-section scan in Fig. 3c, has another appearance. Although two close coalescing cell cores might be recognized, the structure is generally more compact than that of the multi-cell. Also the storm appears and develops rather as one unity in the horizontal radar scans (not shown).

Bringing the findings of Figs. 2 and 3 together, the transition point indeed seems to mark the time when a growing single cell either starts dissipating or develops into a better organized storm structure. Single thunderstorm cells, being rather simply structured, develop a well-defined updraft region in their growing phase (compare Fig. 3a). Since the electrical charging and discharging at this state is restricted to the updraft region (Saunders, 2008), the lightning cells observed are compact and sharply outlined. The mean IC height increases together with increasing cell area (and most likely vertical extension) and discharge frequency, eventually reaching a maximum as the cell enters its mature state. After the short mature state, while the downdraft develops, the updraft weakens. With the updraft being the main charging generator, the stroke frequency and the cell area cease with the weakening updraft until the storm finally dissipates.

The better organized and more persistent multi-cell and supercell storms are likely to undergo a growing phase similar to that of single cells. But then they change their appearance. When they enter the mature stage, they do not start to dissipate but enter an intensified and longer lasting mature state. This state is characterized by separated updraft and downdraft regions. Multi-cell storms develop several coexisting thunderstorm cells influenced and triggered by each other. Supercells, due to their special rotating structure, grow as one main entity to large sizes. In both formations the area of lightning occurrence (lightning cell) is no longer homogeneous in the horizontal and vertical as it contains younger (more lightning activity) and older cells or growing (more lightning activity) and decaying parts. Due to cloud charging mechanisms like inductive charging and transport of charged particles, lightning spreads into the broader updraft and downdraft regions, into the intermediate regions between adjacent updraft cores, and possibly attached stratiform regions (Carey et al., 2005; Lund et al., 2009). But the efficiency of the driving processes for charge separation and therefore lightning activity does not increase to the same degree, since it is primarily restricted to the updraft regions. As a consequence, the correlation between stroke frequency and cell area would become less steep at that point. The mean IC emission height behaves similarly and increases slowly with

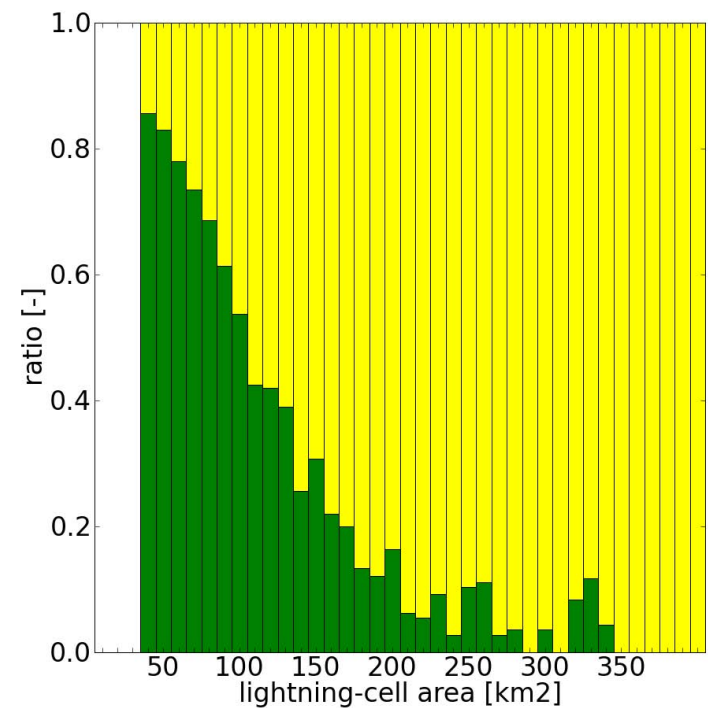

Fig. 4. Relative contribution of lifetime regime 1 (green bars), e.g. short-lived lifetime regime, and lifetime regime 2 (yellow bars), e.g. long-lived lifetime regime, to the correlation graphs of Fig. 1.

storm size despite the natural boundary of the tropopause. This suggests that in general the updraft intensity still grows with its size, which will be discussed in the next section. The more irregularly shaped and less well-defined cell outlines during the mature stage might explain the abrupt onset of scatter observed in the second area-discharge regime in all statistical correlation plots of Fig. 1.

To confirm the above-deduced explanation, two storm classes, the "short-lived" and the "long-lived" storms, have been introduced, and their relative contributions to the correlation statistics in Fig. 4 are examined. The class of shortlived storms comprises both cell tracks which have lifetimes between $15 \mathrm{~min}$ and $60 \mathrm{~min}$, and the class of long-lived storm cell tracks with lifetimes of $60 \mathrm{~min}$ and longer. Very shortlasting life cycles up to times of $15 \mathrm{~min}$ are excluded from this study, because such temporary discharge cells are not of interest here and might be contaminated by track artefacts (Meyer et al., 2013). The threshold of $60 \mathrm{~min}$ is used to discriminate poorly organized but severe thunderstorms (lifetimes between $10 \mathrm{~min}$ and $60 \mathrm{~min}$ ) from well-organized thunderstorms such as squall lines and complexes (lifetimes longer than $60 \mathrm{~min}$ ). Beside the "common knowledge", this threshold is motivated by another study (Mackeen et al., 1999) which relies on a linear interpolation of meteorological scales done by Zipser (1983). Figure 4 illustrates the relative contribution of the so-defined classes of long-lived and short-lived storms to the statistical correlation plots of Fig. 1. According to this figure it is the long-lived storm regime that contributes almost exclusively to the second area-discharge regime, while the percentage of the short-lived storm class already falls below $20 \%$ at a cell area of $170 \mathrm{~km}^{2}$. This supports the interpretation given before. 
(a)

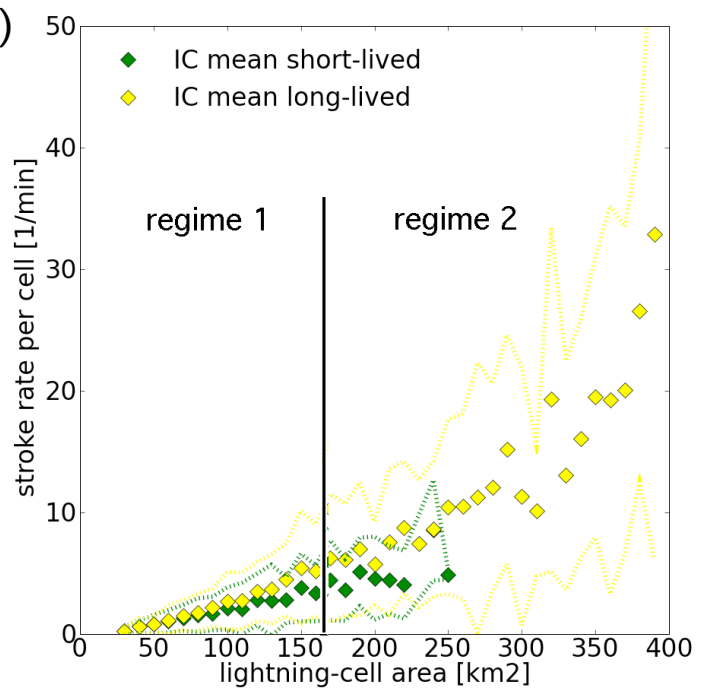

(b)

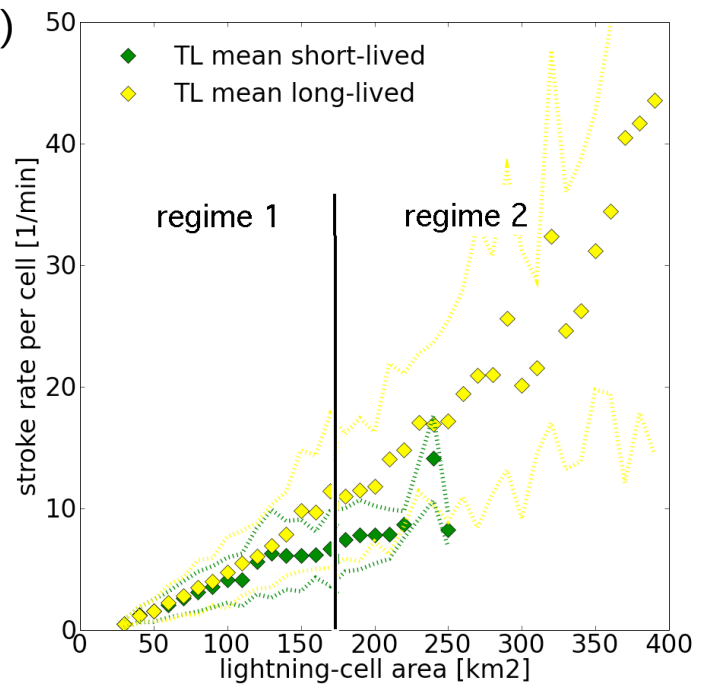

Fig. 5. Correlation plots comparing the relation between (a) TL and (b) IC stroke numbers per cell area interval of $10 \mathrm{~km}^{2}$ for the two different lifetime regimes introduced in Fig. 1. Diamonds mark the respective distribution means, dashed lines the 25th and 75 th percentiles. The short-lived lifetime regime is plotted in green, the long-lived regime in yellow. All area intervals where the number of cell entries falls below 5 are not shown.

The recalculation of the correlation plot shown in Fig. 1a with respect to the two storm lifetime classes (Fig. 5) reveals that during their growing and dissipating phase, e.g. in the first area-discharge regime, the short-lived storm class generally exhibits lower stroke rates than the long-lived storm class. This can be understood, if it can be assumed that cells, which are not able to survive for longer time periods, generally experience less intensive driving forces than cells which finally succeed to form more persistent and more complex structures.

With the maximum stroke distance and the maximum flash duration set to $10 \mathrm{~km}$ and $1 \mathrm{~s}$, respectively, the average num- ber of strokes per flash in the whole preprocessed data set has been found to be 2.8. By dividing the stroke rates per cell area given in Eqs. (1) to (4) with 2.8, the respective correlation functions can be given.

For TL flash rates (per minute) $r_{\mathrm{TL}}^{\mathrm{fl}}$ per lightning-cell area $A\left(\right.$ in $\mathrm{km}^{2}$ ) of the first area-discharge regime,

$r_{\mathrm{TL}}^{\mathrm{fl}}=0.45 \cdot 10^{0.0055 A}$

and of the second regime

$r_{\mathrm{TL}}^{\mathrm{fl}}=1.43 \cdot 10^{0.0026 \mathrm{~A}}$.

For the IC flash rate (per minute) $r_{\mathrm{IC}}^{\mathrm{fl}}$ per lightning-cell area $A$ (in $\mathrm{km}^{2}$ ), we obtain for the first regime

$r_{\mathrm{IC}}^{\mathrm{fl}}=0.21 \cdot 10^{0.0060 \mathrm{~A}}$

and for the second area-discharge regime

$r_{\mathrm{IC}}^{\mathrm{fl}}=0.79 \cdot 10^{0.0027 \mathrm{~A}}$.

Note that the definition of a lightning cell, comprising threeminute lightning stroke data, allows the flash rate of a cell to fall below 1 flash per minute.

Certainly, the mean flash rate per cell area shows the same characteristics as the respective mean stroke rate. The applied clustering method does not take into account that flash length and duration might increase with storm size. So flash rates retrieved from Eqs. (7) to (10) are considered here as reliable estimations, which make the results of this study better comparable with other lightning detection systems. A more sophisticated clustering method, which also considers the storm size, might reveal more details in the flash characteristics.

\section{Summary and conclusions}

This paper investigates the temporal evolution of lightning characteristics of thunderstorms in terms of physically meaningful cell entities. The novel aspects are (a) the use of LINET lightning data providing IC-CG stroke discrimination as well as IC stroke heights and (b) the application of the newly developed li-TRAM algorithm for tracking and monitoring the lightning cells (Meyer et al., 2013). Based upon a total of 7687 individual cell records - out of which 863 cell life cycles occurred completely within the domain - the strength of this study results from the good statistics used to correlate electrical discharge characteristics with the thunderstorm features lifetime and cell area. With the help of the more detailed investigation of three carefully selected example storms, each one representing a special class of thunderstorm, the statistics could be more profoundly interpreted in terms of the individual storm types single-cell, multi-cell and supercell. 
Remarkably, good statistical correlations are found between TL and IC stroke rates, mean IC emission height, and the lightning-cell area (Fig. 1), which can be parameterized (Eqs. 1 to 6). It is found that the TL and IC stroke frequency increases exponentially with the cell area, whereas bigger cells generally have a higher IC fraction. Like the stroke rate the mean IC emission height per cell increases with the cell area, too. This might be an indication of a generally growing discharge volume, which would extend the initially introduced reduction to a two-dimensional projection (cell area) again to volumetric information (charged "volume"). A transition point appears consistently around a cell area of $170 \mathrm{~km}^{2}$ in all statistical correlation diagrams, where the growing rate of both stroke rates as well as of the mean emission height declines abruptly and significant scatter starts.

An interpretation of the discharge characteristics and the transition point has been given by additionally comparing the parameter correlations of three selected thunderstorm life cycles (Fig. 2) with each other, and those of the two introduced lifetime regimes (Figs. 4 and 5). The short-lived storm regime can be assumed to comprise mostly poorly organized single-cell storms, the long-lived storm regime to consist mainly of well-organized storm types, such as multi-cells and supercells.

Based on these findings, the following conclusion has been deduced: while poorly organized and rather short-lived single cells generally develop areas below $170 \mathrm{~km}^{2}$ and exhibit lower stroke rates, better organized storm structures, such as multi-cells and supercells, achieve significantly larger areas while exhibiting intensified discharge rates which reach higher levels. The break in the discharge characteristics marks the point when the storms develop more complex but more persistent structures in which updraft and downdraft regions are separated. Since the charge separation mechanism, which is primarily restricted to the updraft region(s) (Takahashi, 1978; Dash et al., 2001; Saunders, 2008), is less effective with respect to the covered discharge area, the slope of the stroke rate spontaneously decreases. This finding can be confirmed by radar cross-section scans (Fig. 3). Moreover, the more disrupted appearance of a multi-cell seems to hold the stroke rate below the mean, while the more efficient with more unique appearance of the supercell seems to push the stroke rate above the mean. The increase of the mean emission height with increasing cell area is in parallel with the stroke rate. This indicates that bigger storm complexes generally have more vigorous updrafts, which produce discharge activity and are able to carry the charged particles to higher levels. This is in good agreement with previous studies (Williams, 1985; Krehbiel, 1986; Goodman and MacGorman, 1986; Price and Rind, 1992; Fehr et al., 2005; Motley et al., 2006). Furthermore, the positive correlation found between mean emission height, cell area, and lifetime contributes to the discussion about the meaning of the IC mean discharge height in relation to storm state and intensity (Mc-
Cormick et al., 2002; Demetriades et al., 2004; Motley et al., 2006).

Correlation functions can be given for the stroke rates (Eqs. 1 to 4) and the IC mean height (Eqs. 6 and 7). In order to make the correlation functions better comparable with other lightning localization systems, a common stroke to flash clustering method has been used to translate the correlation functions for stroke rates into functions for flash rates (Eqs. 7 to 10). But because of the inflexible clustering criteria, a more sophisticated study is recommended that considers the dependence of flash length and duration with storm size.

Considering the strong individual character of thunderstorms, further studies are also recommended to assess the feasibility and reliability of such general statements. By computing averaged thunderstorm life cycles for the two introduced lifetime regimes, for example, the general existence of conceptual schemes and, most important, its reliability could be evaluated. It can be expected that further diversifications of pertinent flow regimes might refine the results. But despite the good correlations found in this study, it has to be kept in mind that with this approach even the best parameterization can still no more than represent the mean.

Still, it will be an important finding for thunderstorm nowcasting, if it is possible to relate and parameterize storm "intensity" parameters, like storm size, stroke (or flash) frequency and storm persistence with organization forms. This information could be used to complement the spatial storm nowcasting with information about general storm characteristics, such as the expected evolution and danger potential, once the storm type has been assessed. This might include additional knowledge, possibly linking climatological background information and expert knowledge about the local characteristics of thunderstorm development (e.g. the impact of geographical features and flow regimes) and numerical weather prediction (NWP) information with pure extrapolation techniques.

In addition to its role for thunderstorm nowcasting, the correlation functions found in this study can be compared with other commonly used lightning parameterizations (Price and Rind, 1992; Allen and Pickering, 2002). They can be used for lightning discharge parameterizations, using strokes as well as flashes, in climate models where thunderstorm charging mechanisms cannot be resolved. The obvious advantage of the presented correlation functions is the strong underlying statistics and the parameterized relationship between IC and TL (and consequently CG) events. This relationship can also be used to estimate the IC fraction in undifferentiated TL or pure CG lightning data, which are common for the majority of long-ranging lightning localization networks, but always keeping in mind the limitation every detection system faces.

The good and reasonable parameter correlations found in the discharge data are evidence of the good quality of the primary data provided by the long-range total lightning 
detection network LINET within the network. They further testify that the emission height given for the IC strokes behaves reasonably well by statistical means.

Acknowledgements. This work was funded by the German Ministry for Education and Research BMBF under contract 01LS05125 in the project RegioExAKT (Regionales Risiko konvektiver Extremwetterereignisse: Anwenderorientierte Konzepte zur Trendbewertung und -anpassung, Regional risk of convective extreme weather events: user-oriented concepts for trend assessment and adaptation).

The service charges for this open access publication have been covered by a Research Centre of the Helmholtz Association.

Edited by: M. Dameris

\section{References}

Allen, D. J. and Pickering, K. E.: Evaluation of lightning flash rate parameterizations for use in a global chemical transport model, J. Geophys. Res.-Atmos., 107, 4711, doi:10.1029/2002JD002066, 2002.

Betz, H. D., Schmidt, K., Fuchs, B., Oettinger, W. P., and Höller, H.: Cloud lightning: detection and utilization for total lightning measured in the VLF/LF regime, J. Light. Res., 2, 1-17, 2007.

Betz, H. D., Schmidt, K., Oettinger, W. P., and Montag, B.: Celltracking with lightning data from LINET, Adv. Geosci., 17, 5561, doi:10.5194/adgeo-17-55-2008, 2008.

Betz, H. D., Schmidt, K., Laroche, P., Blanchet, P., Oettinger, W. P., Defer, E., Dziewit, Z., and Konarski, J.: LINET: An international lightning detection network in Europe, Atmos. Res., 91, 564573, 2009.

Blyth, A. M., Christian, H. J., Driscoll, K., Gadian, A. M., and Latham, J.: Determination of ice precipitation rates and thunderstorm anvil ice contents from satellite observations of lightning, Atmos. Res., 59, 217-229, 2001.

Burrows, W. R., King, P., Lewis, P. J., Kochtubajda, B., Snyder, B., and Turcotte, V.: Lightning occurrence patterns over Canada and adjacent United States from lightning detection network observations, Atmosphere-Ocean, 40, 59-80, 2002.

Carey, L. D., Murphy, M. J., McCormick, T. L., and Demetriades, N. W. S.: Lightning location relative to storm structure in a leading-line, trailing-stratiform mesoscale convective system, J. Geophys. Res., 110, D03105, doi:10.1029/2003JD004371, 2005.

Cummins, K. L. and Murphy, M. J.: An Overview of Lightning Locating Systems: History, Techniques, and Data Uses, With an InDepth Look at the US NLDN, IEEE Transactions on Electromagnetic Compatibility, 51, 499, doi:10.1109/TEMC.2009.2023450, 2009.

Dahl, J. M. L., Höller, H., and Schumann, U.: Modeling the Flash Rate of Thunderstorms. Part I: Framework, Mon. Weather Rev., 139, 3093-3111, 2011.

Dash, J. G., Mason, B. L., and Wettlaufer, J. S.: Theory of charge and mass transfer in ice-ice collisions, J. Geophys. Res., 106, 20395-20402, 2001.
Deierling, W. and Petersen, W. A.: Total lightning activity as an indicator of updraft characteristics, J. Geophys. Res.-Atmos., 113, 16210, doi:10.1029/2007JD009598, 2008.

Demetriades, N. W. S., Murphy, M. J., Holle, R. L., and Richard, P.: The importance of total lightning in the future of weather nowcasting, in: Proceedings of Symposium on Planning, Nowcasting, and Forecasting in the Urban Zone, The 84th AMS Annual Meeting, Seattle, Washington, 10-16 January, Paper 1.7, 2004.

euclid.org: EUCLID European Cooperation for Lightning Detection, http://www.euclid.org/learning.html, last access date: 21 December 2012.

Fehr, T., Dotzek, N., and Höller, H.: Comparison of lightning activity and radar-retrieved microphysical properties in EULINOX storms, Atmos. Res., 76, 167-189, 2005.

Goodman, S. J. and MacGorman, D. R.: Cloud-to-ground lightning activity in mesoscale convective complexes, Mon. Weather Rev., 114, 2320-2328, 1986.

Höller, H., Betz, H.-D., Schmidt, K., Calheiros, R. V., May, P., Houngninou, E., and Scialom, G.: Lightning characteristics observed by a VLF/LF lightning detection network (LINET) in Brazil, Australia, Africa and Germany, Atmos. Chem. Phys., 9, 7795-7824, doi:10.5194/acp-9-7795-2009, 2009.

Krehbiel, P. R.: The electrical structure of thunderstorms, in: The Earth's Electrical Environment, chap. 8, pp. 90-113, The National Academies Press, Washington, DC, 1986.

Lopez, R. E. and Aubagnac, J. P.: The lightning activity of a hailstorm as a function of changes in its microphysical characteristics inferred from polarimetric radar observations, J. Geophys. Res., 102, 16799-16813, 1997.

Lund, N. R., MacGorman, D. R., Schuur, T. J., Biggerstaff, M. I., and Rust, W. D.: Relationships Between Lightning Location and Polarimetric Radar Signatures in a Small Mesoscale Convective System, Mon. Weather Rev., 137, 4151-4170, doi:10.1175/2009MWR2860.1, 2009.

MacGorman, D. R. and Rust, W. D.: The Electrical Nature of Storm, Oxford University Press, 1998.

Mackeen, P., Brooks, H., and Elmore, K.: Radar Reflectivity Derived Thunderstorm Parameters Applied to Storm Longevity Forecasting, Weather Forecast., 14, 289-295, 1999.

McCormick, T. L., Carey, L. D., Murphy, M. J., and Demetriades, N. W. S.: Three-dimensional Radar and Total Lightning Characteristics of Mesoscale Convective Systems, in: AGU Fall Meeting Abstracts, San Francisco, California, December 6-10, A71B0093, 2002.

Meyer, V. K., Höller, H., and Betz, H. D.: Automated thunderstorm tracking: utilization of three-dimensional lightning and radar data, Atmos. Chem. Phys., 13, 5137-5150, doi:10.5194/acp-135137-2013, 2013.

Motley, S. M., Carey, L. D., and Murphy, M. J.: Total lightning characteristics of ordinary convection, in: Proceedings of 19th International lightning Detection Conference, Tucson, Arizona, 24-25 April, 2006.

Price, C. and Rind, D.: A Simple lightning parameterization for calculating global lightning distributions, J. Geophys. Res., 97, 9919-9933, 1992.

Saunders, C.: Charge separation mechanisms in clouds, Space Sci. Rev., 137, 335-353, 2008.

Schroth, A. C., Chandra, M. S., and Meischner, P. F.: A C-band coherent polarimetric radar for propagation and cloud physics 
research, J. Atmos. Ocean. Technol. 5, 803-822, 1988.

Schulz, W., Cummins, K., Diendorfer, G., and Dorninger, M.: Cloud-to-ground lightning in Austria: A 10-year study using data from a lightning location system, J. Geophys. Res.-Atmos., 110, D09101, doi:10.1029/2004JD005332, 2005.

Shao, X. M. and Krehbiel, P. R.: The spatial and temporal development of intracloud lightning, J. Geophys. Res., 101, 2664126668, 1996.

Takahashi, T.: Riming electrification as a charge generation mechanism in thunderstorms, J. Atmos. Sci., 35, 1536-1548, 1978.
Williams, E. R.: Large-scale charge separation in thunderstorms, J. Geophys. Res.-Atmos., 90, 6013-6025, 1985.

Yoshida, S., Morimoto, T., Ushio, T., and Kawasake, Z. I.: A fithpower relatinship for lightning activity from Tropical Rainfall Measuring Mission satellite observations, J. Geophys. Res., 114, D09104, doi:10.1029/2008JD010370, 2009.

Zipser, E. J.: Nowcasting and very-short-range forecasting, in: The National STORM Program: Scientific and Technical Bases and Major Objectives, chap. 6, University Corporation for Atmospheric Research, 1983. 